\title{
Victim-Group Legitimacy: An Argument for Extending our Understanding of Legitimacy after Crisis
}

\author{
Cody Blake Wilson \\ Purdue University \\ Indiana, West Lafayette U.S.A.
}

\begin{abstract}
Organizational legitimacy has been useful approach to studying relationship management in crisis. This presentation suggests an expansion of organizational legitimacy theory: victim-group legitimacy. Multiple recent cases of crisis involving historically marginalized groups (HMGs) suggest that organizations may not be fully prepared to respond to crises involving HMGs. Recent cases also suggest that publics now routinely see modern crises as chapters within larger marginalization narratives. Victim-group legitimacy acts as a framework for evaluating, interpreting, and responding to not only the crisis at hand, but the historical crisis between an organization and HMGs.
\end{abstract}

Keywords - Crisis management, Crisis response, Legitimacy, Marginilized, Relationships

SUGGESTED CITATION: Wilson, C. B. (2018). Victim-group legitimacy: An argument for extending our understanding of legitimacy after crisis. Proceedings of the International Crisis and Risk Communication Conference (pp. 16-19). Orlando, FL, USA. Nicholson School of Communication. https://doi.org/10.30658/icrcc.2018.5

\section{INTRODUCTION}

Waymer and Heath [1] recently made a call for greater research into how legitimacy may be used as a lens for understanding organizational public relations, particularly with historically marginalized groups (HMGs). This conceptual paper is a direct answer to that call. Recent cases have demonstrated the need for better research and practice of crisis communication, particularly when those victimized by the crisis belong to one of these groups. After the shooting of Michael Brown in Ferguson, the city of St. Louis was impacted by protests for months (protests that are yet still routinely reoccurring) [2]. The fallout over an internal memo claiming women as biologically inferior at Google has led to multiple law suits [3]. H\&M lost multiple high-profile partnerships after a young Black boy wearing a monkeythemed shirt was featured as a model on their website [4]. The list could continue well beyond the bounds of these proceedings. The point is clear: we as public relations practitioners have yet to fully grasp how to properly navigate chopping relational waters after these kinds of crises occur.

Using theories of legitimacy from public relations, criminal justice, and critical studies, this paper begins proposing a theoretical framework to prepare for and respond to crisis involving HGMs. This theory is called victim-group legitimacy.

Victim-group legitimacy can be conceptualized as defending the social legitimacy of a victim or a victim’s group as a part of an organization's crisis response strategy.

First, the theoretical literature will be synthesized. Then, this paper will propose three postulates, four situational considerations, a scanning framework, and a response framework. Lastly, the paper will discuss the author's next steps in testing and refining the victim-group legitimacy framework.

\section{LITERATURE REVIEW}

Through a legitimacy lens, organizations experience threats to legitimacy when publics see a gap between their expectations for organizations and reality [5]. This gap can be due to a number of factors, including a lack of social and ethical responsibility [1]. Crisis response, then, can be seen as an attempt by organizations to restore their legitimacy in the eyes of their publics. For example, an organization may find its legitimacy threatened when the public learns it has been dumping toxic waste into local water bodies. A logical response may be to 1) stop dumping waste in the water bodies and 2) take on greater institutionalized efforts to clean up the local nature and green spaces. In this hypothetical, the organization attempts to manage public relationships by responding directly to the gap in legitimacy caused by the 
crisis. It is important to note that, according to this conceptualization, legitimacy is bestowed on organizations by the publics. Thus, legitimacy is "in the eye of the beholder," so to speak.

Communication and management scholars are not the only ones concerned with legitimacy. In fact, legitimacy has been an important subject in a variety of research fields. One field in particular is that of criminal justice and law enforcement. In this context, legitimacy is routinely discussed as a necessity for order. Legitimacy is the property of rightness in relation to the people and/or the law. Without it, the power of the law and those that enforce it ceases to exist [6]. However, legitimacy has also been described as something citizens demand in their own interactions with law enforcement [7]. In fact, many conceptualizations of marginalization found in the critical studies literature mirror the concept of threats to legitimacy [8].

While traditional public relations application of theories surrounding legitimacy are often focused on the legitimacy of the organization, the field has failed to thoroughly consider how these same crises could threaten the legitimacy of publics, particularly publics belonging to HMGs. Thus, a more robust framework for such situations is necessary. This paper proses just that.

\section{VICTIM-GROUP LEGITMACY}

\section{ASSUMPTIONS}

The victim-group legitimacy framework assumes three things. First, it assumes that crises can invoke historical narratives of marginalization. There is plenty of anecdotal evidence to support this notion: activists have explicitly drawn parallels between police shootings of Black men and the larger historical issue of racism [2]. The Google memo awoke conversation of not only the memo's author, but also the history of women being blocked from technology and engineering [3]. Beyond simply anecdotal evidence, public relations research has already noted the importance of organizational history to the perception of a crisis in the eyes of the public [9]. The second assumption is that crises can threaten not only the legitimacy of organizations, but people groups and those with shared identities. This assumption comes from the understanding of legitimacy negotiations between law enforcement and citizens [7]. The last assumption is that organizations have an ethical call to respond to crises or issues in a way that legitimizes both the organization and victims. This sort of notion is right in line with Waymer and Heath's [1] call for a conceptualization of legitimacy informed by CSR.

\section{SITUATIONAL CONSIDERATIONS}

The framework also has four situational considerations. In order for the victim-group legitimacy to be applicable as a response strategy, these four things must be true. First, the crisis must have a clear victim (or victims). Without clear victims, it is unlikely that publics will engage historical narratives, and it will be difficult for organizations to specifically target gaps in legitimacy created by the crisis. Second, the victims must belong to a historically marginalized group. For example, the H\&M case was singled out by publics specifically because of the identity of the boy in the photo [4]. Third, stakeholders must connect the crisis to a larger historical narrative of marginalization. For example, memes on social media depicted visual comparisons of protestors of the Dakota Access Pipeline clashing with police alongside historical drawings of Native Americans fighting early American settlers [10]. These memes represent thematic elements of the historical narrative of the exploitation of Native Americans. Lastly, the organization in question must hold an antagonistic role in the historical narrative. If this is not the case, it is unlikely that the history of marginalization need be addressed in the response. Rather, the immediate crisis should remain in highest priority.

\section{SCANNING}

During the issue management stages, it is important for organizations to be building awareness of these historical narratives and how their present actions may trigger "new chapters" through crisis. Therefore, victim-group legitimacy requires that organizations prepare for these situations before they occur. Organizations can do this by considering a number of factors. First, organizations must be aware of the historical narratives that exist between their organization/industry and different HMG. It may be helpful to write out these narratives in as much detail as possible. Second, the organization must understand the role it has played in the past, the present, and the role it wants to play in the future. An understanding of role history and vision will allow for more cohesive response. The organization must also understand exactly how the HMG has been de-legitimized in this particular narrative. The gap in legitimacy created by crisis is not a general one, but one of specific detail. How specifically has the legitimacy of the HMG in question been threatened historically? Fourth, organizations should be aware of how their modern-day relationships could run parallel to these historical narratives, and how common crises could invoke larger issues of legitimacy for publics.

As a crisis unfolds, managers can be doing a number of things to use the information gathered during scanning to prepare for a response. First, it is important for the management team to clearly define both the immediate and the historical crisis occurring. The immediate crisis is the story happening in the present day, while the historical crisis is the narrative being invoked present day crisis. It may be helpful to define who the victim or victims are and what HMGs to which they may belong. Once the organization has in mind what historical narratives may be invoked, monitoring of stakeholders and thought leaders can inform whether or not these historical narratives are being recognized by publics. If 
not, it may not be necessary to engage any historical narratives.

\section{RESPONSE}

Victim-group legitimacy is meant to be used alongside already well-tested crisis response strategies. There may be a number of things that must be addressed based on the immediate crisis. However, if the scanning work predicts a high likelihood and need to respond to a victim's threatened legitimacy, the following response framework can be helpful additions to formal crisis response.

Whatever crisis response is constructed using victim-group legitimacy should be checked for contradictions or inconsistencies with the traditional response. While it may be constructed separately, it must not lack coherence with other messaging from the organization. When contradictions are found, managers must evaluate how coherence can be achieved while still working to defend both organizational and victim legitimacy. The first noticeable addition that victim-group legitimacy recommends is for crisis responders to acknowledge historical narratives. Then, crisis responders must respond directly to the threats to the legitimacy of the victims as well as the historically marginalized group to which they belong.

\section{DISCUSSION}

Victim-group legitimacy intends to provide crisis mangers with a framework for defending the legitimacy of victims and HMGs, while also defending organizational legitimacy. Cases such as police shootings of Black men are prime examples of where this sort of framework could be used to navigate a volatile time and maintain relationship. These situations are particularly ripe because of their connection to the histories of subjugation at the hands of police, enforcement of racist laws by police, and the over-policing of Black communities in the United States. Additionally, stereotypes of the "large, violent Black man" are often evoked when officers claim they "feared for their lives." Knowing this, an example response using the victim-group legitimacy framework would recognize the threats to legitimacy faced by the Black community by a crisis of this kind: namely, that Black Americans do not retain the same rights and humanity as other citizens. A response might then acknowledge the tense relationships between police and African Americans, even specifically in the community impacted. Furthermore, the response might also speak directly to the citizenship of the victim. For example, crisis managers may consider featuring messaging about the victim that combats negative stereotypes of Black men, particularly as they relate to crime and violence. But messaging must go beyond the victim as well. It is important for messaging to directly speak to the legitimacy of the local Black community as well. How have community leaders contributed to economic growth? How has the community thrived? What resources are available? In the case of police response to crisis, it may be key to also reassure community members of the department’s commitment to serving and protecting all citizens, no matter their race.

\section{CONCLUSION}

The victim-group legitimacy framework is a tool for crisis managers to strategically manage relationships with HMGs in times of crisis. Using the lens of legitimacy, the framework calls for an understanding of how historically narratives of marginalization can be invoked by modern-day crises and threaten the legitimacy of said groups. With that understanding, crisis managers can construct responses to crises that acknowledge these historical narratives and defend the legitimacy of both the victims and their group. Further research is needed to continue to refine the framework. The great tradition of case studies in crisis research is one way for this to occur, though other more empirical studies may also be useful to test scanning and response strategies. Like all knowledge, this framework will take years, perhaps even decades, to perfect. Even so, the need for organizations to response in ethically and socially responsible ways to crises is immediate and unrelenting. Therefore, it is of the utmost importance that public relations scholars engage in this conversation.

\section{Author Biography}

Cody Blake Wilson earned his M.S. in Communication from the Brian Lamb School of Communication in 2018. He now works in operations and administration for the KIPP Public Charter School network in Indianapolis, IN. He may be reached at wilso248@purdue.edu.

\section{REFERENCES}

[1] Waymer, D., \& Heath, R. L. (2014). Organisational legitimacy: The overlooked yet all-important foundation of OPR research. PRism 11(2). Available at http://www.prismjournal.org/homepage.html

[2] Mendenhall, D. (2015). Blogging Ferguson in Black and White. Journal of New Media and Culture, 10(1). Available at http://ibiblio.org/nmediac/summer2015/ferguson.html

[3] Wakabayashi, D. (2018, February 16). Google legally fired diversity memo author, labor agency says. New York Times. Retrieved from https://www.nytimes.com/2018/02/16/business/google-memo-firing.html 
[4] Fumo, N. (2018, January 8). A racially insenstive product photo just cost H\&M a major celebrity partner. Forbes. Retrieved from https://www.forbes.com/sites/nicolafumo/2018/01/08/a-racially-insensitive-productphoto-just-cost-hm-a-major-celebrity-partner/\#5d011ec27fb3

[5] Heath, R. L. (1997). Strategic issues management: Organizations and public policy challenges. Thousand Oaks, CA: Sage.

[6] Frost, B. (2012). Legitimacy. Oxford Bibliographies. Retrieved from http://www.oxfordbibliographies.com/view/document/obo-9780195396607/obo-9780195396607-0134.xml

[7] Rojeck, J., Alpert, G. P., \& Smith, H. P. (2012). Examining officer and citizen accounts of police use-of-force incidents. Crime and Delinquency, 58(2), 301-327. https://doi.org/10.1177/0011128710386206

[8] Mundy, D. E. (2016). Bridging the divide: A multidisciplinar analysis of diversity research and the implications for public relations. Research Journal of the Institute of Public Relations, 3(1), 1-28.

[9] Coombs, W. T. (2004b). Impact of past crises on current crisis communications: Insights from situational crisis communication theory. Journal of Business Communication, 41: 265-289. https://doi.org/10.1177/0021943604265607

[10] Donella, L. (2016, November 22). The Standing Rock resistance is unprecedented (It's also centuries old). NPR: Code Switch. Retrieved from https://www.npr.org/sections/codeswitch/2016/11/22/502068751/the-standingrock-resistance-is-unprecedented-it-s-also-centuries-old 